(C2018, Elsevier. Licensed under the Creative Commons Attribution-NonCommercialNoDerivatives 4.0 International http://creativecommons.org/about/downloads

cc) $(1) \Theta$ 


\title{
Problematic Internet Use and Mental Health among British Children and
}

\section{Adolescents}

\begin{abstract}
Despite concerns about the effects of internet use, little is known about how problematic internet use impacts on British children and adolescents. By adapting the Problematic Internet Use Questionnaire (PIUQ, Demetrovics et al. 2008), this study seeks its validation while studying its association with psychopathological and health problems. A sample of 1,814 children and adolescents (aged 10-16 years old) from UK schools completed questionnaires about PIU, behavioural problems, depression, anxiety and health problems. Confirmatory Factor Analysis identified three independent factors: Neglect, Obsession and Control Disorder. Using path analysis PIU was significantly predicted by conduct problems, hyperactivity, impact on daily life activities, depression and poorer physical health. Males were more likely than females to score higher on PIU. The study shows for the first time that the adapted PIU questionnaire constitutes a valid tool for the assessment of problematic internet use among children/adolescents. The results also suggest an urgent need for the development of intervention strategies.
\end{abstract}

Key words: Internet Addiction; Problematic Internet Use; Pathological Internet Use; Mental Health; Psychopathology; Children and Adolescents 


\section{INTRODUCTION}

The accessibility of online activities can lead young people to spend more time online than they originally intend (Smahel, Blinka, \& Ledabyl, 2008). In the UK, the Office of Communication (Ofcom, 2017) reported 83\% of 12-15 year olds have smart phones and 99\% go online for nearly 21 hours a week, an increase from the previous year. Increased access and persistent internet use increase the risk of developing online addictive behaviours (Tonioni et al., 2012; Tsitsika et al., 2009), which can adversely affect psychological development (Iacovelli \& Valenti, 2009; Guan, \& Subrahmanyam, 2009). Excessive internet use has attracted increasing concern, leading to the introduction of terms such as "Problematic Internet Use" (PIU) or “Internet Addiction Disorder” (IAD). Weinstein, Feder, Rosenberg and Dannon (2014) described PIU/IAD as involving controlled or excessive urges, preoccupations or behaviours regarding internet use, which results in impairment or distress to the individual. Previous studies of PIU in relation to psychopathology have adopted a wide range of research methodologies, varying in terms of design (cross-sectional vs longitudinal), sampling characteristics and measurement tools; these often constrain the kinds of conclusion that can be drawn from them.

Durkee et al. (2012) studied 11,956 adolescents from 11 European countries. Using Young's Diagnostic Questionnaire (YDQ, based on a score of 0-8) for internet addiction they classified excessive internet use into three categories; Adaptive (0-2), Maladaptive (3-4) or Pathological Internet Use ( $\geq 5$ ). In their cross-sectional survey, they found that Maladaptive Internet Use was exhibited by $13 \%$ of the sample and 4.4\% showed Pathological Internet Use. Spending more time online contributed to the pathological use. Consistently, others have also shown that long hours of internet use can negatively affect young people's schooling, family interactions, psychological 
wellbeing and physical health (Young \& de Abreu, 2011). In a longitudinal study of 14-24-year olds, $(n=719)$, excessive internet use was associated with depressive symptoms (Romer, Bagdasarov \& More, 2013). However, it has also been proposed that internet use may conversely serve as a coping mechanism for depressive feelings (Horwitz, Hill, King; 2011; Dillman-Carpentier, et al., 2008) or for a lack of physical social interaction (via social media, Griffiths, 2012). Furthermore, PIU may increase social fears and reinforce avoidance of face-to-face social interactions (Lee \& Stapinski, 2012) as well as low physical activity (Rosen et al., 2014). It is also linked with academic problems, irritability and sleep problems (Yan, et al., 2011; Young \& de Abreu, 2011).

In a large cross-sectional study of 11,356 European adolescents (approximately 15 years old on average), Kaess et al. (2014) found that pathological internet use is associated with hyperactivity/inattention, conduct problems, suicidal ideation and suicide attempts. The associations between PIU, conduct problems and hyperactivity/inattention were more robust among females than males, whereas the converse was the case for symptoms of depression, anxiety and peer relationship problems. Finally, PIU has been linked with substance abuse; indeed, it has been argued that both share similar characteristics (e.g., Ko et al. 2006; Lee et al. 2013; Dalbudak et al., 2014).

Despite extensive research highlighting the negative impacts of PIU, it is not listed in the International Classification of Diseases (ICD-10) or the Diagnostic and Statistical Manual of Mental Disorders (DSM-5), although 'Internet Gaming Disorder' has been included in DSM-5 (APA, 2013). This is a specific type of problematic internet use which aids the narrative that it is not the 'internet' itself that is addictive but what it offers (e.g. gaming, shopping etc.). The World Health Organisation (WHO) has also 
recently included the "gaming disorder" in its new draft (ICD-11). This further demonstrates the need to understand PIU as a behavioural addiction (APA, 2013). The emergence of an association between mental health and PIU can be explained by self-regulation theory (e.g., Chak \& Leung, 2004; Song et al., 2004). This theory proposes that individuals often act based on satisfying three basic needs: relatedness (desirable attachment to others) competence (sense of mastery), and autonomy (independence and satisfaction from choices made) (Deci \& Ryan, 2000). The importance of these basic needs has been studied in various settings, recently in the context of internet use (Barnes \& Pressey, 2011; Wang, 2014) and online gaming (Hsu et al., 2009). Social media use may provide a sense of relatedness and of autonomy and competence through controlled interaction online (i.e., users are in charge of what they do) (e.g., Nadkarni \& Hofmann, 2012). Wong, Yuen and Wang (2015) found that psychological distress in young adults explained the relationship between needs' satisfaction and PIU. Wong et al. (2015) recommended that psychological distress could therefore be used as an indicator of future PIU.

A number of questionnaires for problematic internet use or internet addiction have been developed, mostly based on Young's (1998) Internet Addiction Test, which was designed in accordance with DSM-IV criteria for gambling addiction. The test was further developed by Demetrovics et al. (2008) to measure the harms and problems associated with internet use (PIUQ: Problematic Internet Use Questionnaire). They evaluated their 30-item questionnaire in Hungary (1,037 respondents, 12-69 years old; $\mathrm{M}=23.3$ years), yielding 18 items (post factor analysis) across three factors, namely: Obsession (being obsessed with internet use); Neglect (neglecting non-internet activities); and Control disorder (inability to control/limit internet use). The same factors were confirmed among 280 American college students (Kelley \& Gruber, 
2010). More recently Demetrovics et al. (2016) proposed a shorter version of the PIUQ which was tested among a younger Hungarian population $(n=5,005$ aged $16-23$ years old). Using 6 items they confirmed the originally-extracted factors. The questionnaire is designed for adults and has not been tested in child samples.

Currently there is a lack of PIU research in the UK, specifically among children and adolescents; the PIUQ was chosen for investigation here due to its cultural appropriateness, and its established psychometric properties and validity. Previous research has adopted different research designs and concentrated only one or two psychological aspects; in contrast, the present study includes the analysis of different $\underline{\text { PIU subscales and how they relate to a much wider range of psychological and }}$ physical problems than has been considered previously in a UK sample.

The study has two overarching aims: first, to test the validity of the problematic internet use questionnaire (PIUQ) among British children and adolescents, something that has not been done previously; second, to examine the associations between PIU and other measures of mental and physical health, namely: depression, anxiety, emotional and behavioural problems, physical and psychosomatic health problems. To our knowledge, these factors have not previously been investigated in relation to PIU amongst children and adolescents in the UK.

\section{METHODS}

\section{Participants}

A cross-sectional research design was adopted, recruiting 1,814 participants aged 1016 years $(\mathrm{M}=12.6$ years, $\mathrm{SD}=1.3$ years $) ; 53 \%$ male $(\mathrm{M}=12.5$ years, $\mathrm{SD}=1.0$ years $)$ and $47 \%$ female $(\mathrm{M}=12.7$ years, $\mathrm{SD}=1.4$ years $)$. Thirty schools were contacted across the UK; however only 6 public secondary schools agreed to participate, representing only 
northern and central UK. All children/adolescents completed a hardcopy or an online version of the questionnaire; 155 questionnaires were deemed invalid or incomplete.

\section{Materials}

Demographic information included age and gender. Participants were asked to describe, on different scales, their experiences over the past 6 months. The Problematic Internet Use Questionnaire (PIUQ; 18-items), adapted from Demetrovics et al. (2008), included 15 questions categorised as: Neglect (e.g. neglecting school work), Obsession (e.g. dreaming about internet) and Control Disorder (e.g. try to limit time online). Items were answered on 5-point scales $(0=$ never; $1=$ once or twice; $2=$ once a month; $3=$ once a week and $4=$ most days $)$. Due to schools' reviews suggestions, as expert opinions, three items were removed and deemed inappropriate for young children (15-items). One item was judged as too difficult to understand (How often does it happen to you that you feel depressed, moody, or nervous when you are not on the Internet and these feelings stop once you are back online?); two others were judged inappropriate for the targeted sample (How often do you choose the Internet rather than going out with somebody to have some fun?; How often do you choose the Internet rather than being with your partner?). The Strengths and Difficulties Questionnaire (SDQ; Goodman, Meltzer, Bailey, 1998; http://www.sdqinfo.com/) is a screening tool for children aged 2-17 years old (25 items). This is a well-validated and extensively-used questionnaire; it includes 25 items measuring emotional symptoms/problems (5 items, e.g. "I am often unhappy, down-hearted or tearful") conduct problems (5 items e.g. "I fight a lot"), hyperactivity/inattention (5 items e.g. "I am restless, I cannot stay still for long"), peer problems (5 items, e.g. "I get on better with adults than with people my own age"), prosocial behaviour (5 items, e.g. "I am helpful if someone is hurt, upset or feeling 
ill"). Items were scored on a 3-points scale ("not true", "somewhat true" and "certainly true"). A further 6 items asked about whether respondents have any of the difficulties described and how these difficulties impact on their lives (e.g. "the difficulties upset or distress you"). The supplementary impact questions were scored on a 4 -point scale $(0=$ not at all; $1=$ only a little; $2=$ quite a lot and $3=$ a great deal $)$. The $\underline{\text { total for each subscale and the total difficulties (without prosocial behaviour) were }}$ calculated along with the total impact. The reliability scores for the 5 subscales ranged between $\alpha=0.81-0.92$.

The Depression questionnaire (Patient Health Questionnaire, PHQ-9, Spitzer, Kroenke, Williams, 1999) included 9 questions relating to symptoms of depression in accordance with DSM-IV (e.g. Feeling down, depressed, irritable, or hopeless?). Participants rated each item by its frequency over the past six months $(\alpha=0.90)$. The Anxiety questionnaire comprised 7 questions from GAD-7 (Spitzer, Kroenke, Williams, Löwe, 2006) measuring Generalised Anxiety Disorder using symptoms from DSM-IV (e.g. Feeling nervous, anxious or on edge.); each question reflected a particular symptom $(\alpha=0.92)$. Depression and anxiety items were scored on four-point scales $(0=$ Not at all; $1=$ Several days; $2=$ More than half of the days; $3=$ Nearly every day). A Brief Screening Test for Adolescent Substance Abuse was adapted from the CRAFFT Screening Interview (e.g. Do you ever use alcohol or drugs to relax, feel better about yourself, or fit in?). Five yes/no $(1,0)$ questions asked about substance abuse $(\alpha=0.80)$ (Knight, Sherritt, Harris, Chang, 2002) and one asked about smoking (tobacco). Finally, the Physical and Psychosomatic Health Questionnaire comprised 26 questions: 7 addressed psychosomatic problems (e.g. having nightmares) and 19 addressed physical health (e.g. having cold/cough) ( $\alpha=0.91$ and $\alpha=0.88$ respectively) (Gini, 2008). The response scale ranged from 0-4 ( $0=$ Never; $1=$ Once or twice; $2=2-3$ 
times a month; $3=$ about once a week; $4=$ several times a week $=4$ ), scores of 0 and 1 were recoded to 0 and other scores into 1 .

\section{Procedure}

Following ethical approval from Kingston University, schools sent parental consent forms and obtained agreement from the entire sample. The questionnaires were available either online (in a designated school IT room) or as hardcopy in the classroom; $70 \%$ of the children completed the online questionnaire (via Qualtrics.com) and 30\% completed the hardcopy. In both cases, the teachers gave instructions and help on how to fill in the questionnaires. Children were told that participation was voluntary and that they could withdraw at any time without explanation. Children were encouraged to provide as accurate information as possible and not to guess or "fake" their responses, and to talk to the school counselling team if they felt uncomfortable as a result of their participation.

\section{Statistical methods:}

Confirmatory Factor Analysis (CFA) via AMOS was used to validate the PIUQ. Each of the other scales described above, along with the factors extracted from the PIUQ, were individually computed and prepared for Path Analysis. All psychopathological, health variables and demographic details were included to explain variances within overall PIU and each of its dimensions. Binary Logistic Regression was used to predict participants who fall in the top $20 \%$ of the PIU scale and its dimensions (i.e. above the $80^{\text {th }}$ percentile cut-off point). Thus, PIU subscales and psychopathological problems were classified into normal $\left(<80^{\text {th }}\right.$ Percentile $)$ versus borderline-clinical $\left(>=80^{\text {th }}\right.$ percentile) categories from the overall sample (See appendix 1).

\section{Confirmatory Factor Analysis:}


Due to our different sample from Demetrovics et al. (2008) it was important to validate the adapted questionnaire. CFA was applied to confirm the 3-factor model; the model provided an adequate fit to the data while controlling for error covariance in obsession (item 5 vs. item $1 \&$ item 5 vs. item 6) and control disorder (item 1 vs. item 2) $\left(\mathrm{X}_{(83)}^{2}=439.34, \mathrm{p}<0.001, \mathrm{CFI}=0.960, \mathrm{GFI}=0.964, \mathrm{RMSEA}=0.052[0.047-\right.$ 0.057]); standardised estimates of factor loadings ranged from 0.49-0.80 (Figure 1). All three factors: neglect $(\alpha=0.81)$, obsession $(\alpha=0.83)$, control disorder $(\alpha=0.72)$ as well as the overall PIU $(\alpha=0.88)$ were reliable.

CFA was conducted across genders and age groups (children: 10-12 years; and adolescents: 13-16 years). Model fit was adequate for males $\left(\mathrm{X}_{(83)}^{2}=278.42, \mathrm{p}<0.001\right.$, $\mathrm{CFI}=0.958, \mathrm{GFI}=0.957, \mathrm{RMSEA}=0.053[0.046-0.060])$ items loaded between 0.54 to 0.80 ; and females $\left(\mathrm{X}_{(83)}^{2}=309.00, \mathrm{p}<0.001, \mathrm{CFI}=0.950, \mathrm{GFI}=0.947, \mathrm{RMSEA}=0.060\right.$ [0.053-0.067]), where loadings ranged from 0.43 to 0.80 . The model fit was adequate also for children $\left(\mathrm{X}^{2}{ }_{(83)}=296.70, \mathrm{p}<0.001, \mathrm{CFI}=0.953, \mathrm{GFI}=0.954, \mathrm{RMSEA}=0.055\right.$ [0.048-0.062]) with loadings ranging between 0.48 to 0.78 and for adolescents $\left(\mathrm{X}^{2}{ }_{(83)}=312.40, \mathrm{p}<0.001, \mathrm{CFI}=0.949, \mathrm{GFI}=0.945, \mathrm{RMSEA}=0.061[0.054-0.068]\right)$ with loadings ranging between 0.55 to 0.84 .

Insert Figure 1 Here

\section{RESULTS}

\section{Predicting Problematic Internet Use (PIU):}

Path analysis was used to examine whether or not psychological and health variables could predict PIU and its factors. Missing data and outliers were cleaned for analysis in AMOS. Table 1 shows descriptive statistics and Pearson's r correlation 
coefficients. Four separate path analysis were conducted (Table 2). The first model explained $26.2 \%$ of the variances with the overall PIU, which was significantly predicted by higher levels of conduct problems $(p<0.001)$, hyperactivity $(p<0.001)$, SDQ impact $(\mathrm{p}<0.01)$, physical health $(\mathrm{p}<0.01)$, depression $(\mathrm{p}<0.001)$ and being a male $(\mathrm{p}<0.01)$. Examining neglect, the second model explained $24.8 \%$ of the variances, where higher levels of neglect were predicted by higher levels of conduct problems $(\mathrm{p}<0.001)$, hyperactivity $(\mathrm{p}<0.001)$, physical health problems $(\mathrm{p}<0.01)$, depressive symptoms $(\mathrm{p}<0.001)$ and low levels of peer problems $(\mathrm{p}<0.001)$. For obsession, the third model explained $27.9 \%$ of the variances; higher levels for obsession were significantly predicted by higher levels of conduct problems ( $<<0.001)$, hyperactivity $(\mathrm{p}<0.01)$, SDQ impact $(\mathrm{p}<0.001)$, physical health problems $(\mathrm{p}<0.05)$ and depression $(\mathrm{p}<0.001)$. Younger participants $(\mathrm{p}<0.01)$ and males $(\mathrm{p}<0.01)$ predicted higher obsession levels. The fourth model explained $8.5 \%$ of the variance in control disorder, which was significantly predicted by higher prosocial behaviour $(\mathrm{p}<0.001)$ and depressive symptoms $(\mathrm{p}<0.001)$.

Insert Table 1 Here

Insert Table 2 Here

\section{Predicting the borderline-clinical range of PIU}

Logistic regressions (Enter method) were conducted to predict borderline-clinical PIU total and its subscales. Variables were dichotomised into the normal range (below the $80^{\text {th }}$ percentile) or the borderline/clinical range $\left(80^{\text {th }}\right.$ percentile and above).

In the first model, the likelihood of being in the borderline-clinical range of PIU was predicted by being in the borderline-clinical range for conduct problems $(\mathrm{p}<0.5)$, 
hyperactivity $(\mathrm{p}<0.001)$, SDQ impact $(\mathrm{p}<0.01)$, substance misuse $(\mathrm{p}<0.01)$, physical health $(\mathrm{p}<0.01)$ and depression $(\mathrm{p}<0.001)$.

Being in the borderline-clinical range for neglect was significantly predicted by being in the borderline-clinical range for hyperactivity $(\mathrm{p}<0.001)$, substance misuse $(\mathrm{p}<0.05)$, psychosomatic health $(\mathrm{p}<0.05)$, physical health $(\mathrm{p}<0.01)$, depression $(\mathrm{p}<0.001)$ and being in the older category $(\mathrm{p}<0.01)$.

The chances of being in the borderline-clinical range for obsession were predicted by conduct problems $(\mathrm{p}<0.001)$, hyperactivity $(\mathrm{p}<0.01)$, SDQ impact $(\mathrm{p}<0.01)$, substance misuse $(p<0.05)$, psychosomatic health $(p<0.001)$, anxiety $(p<0.05)$, depression $(\mathrm{p}<0.001)$ and being male $(\mathrm{p}<0.01)$.

Finally, being in the borderline-clinical range for control disorder was predicted by being in the clinical range of anxiety only $(\mathrm{p}<0.05)$.

Insert Table 3 Here

\section{DISCUSSION}

The adapted Problematic Internet Use questionnaire (PIUQ) yielded a factor structure that was similar to that identified in earlier studies using adult samples (Demetrovics et al., 2008; Kelley and Gruber, 2010). The factors were categorized as Neglect, Obsession and Control Disorder and were confirmed through Confirmatory Factor Analysis for different age groups (children and adolescents) and both genders. This provides a valid tool to investigate PIU among British children and adolescents. Excessive internet use is associated with neglect of daily routine (offline) activities and indicators of obsession, in which children report negative psychological impacts resulting from internet use. The control disorder factor reflects an acknowledgment of 
excessive use as a problem, and difficulties in limiting and controlling its use. All three factors were positively correlated with each other and with other psychopathologies. A strength of this study is that it looked at specific subscales in relation to previously-identified problems amongst children/adolescents. The association between PIU and "Neglect" is consistent with Young and de Abreu (2011), who reported that using the internet excessively can affect young users in terms of their social interactions with others.

$\underline{\text { In line with previous research, this study showed a significant association between }}$ overall PIU and depression (e.g. Romer, Bagdasarov \& More, 2013; Yan et al., 2011; Moreno et al., 2015). Furthermore, we found that depression is positively associated with scores on all subscales, most strongly with neglect. Gámez-Guadrix (2014) found similar positive correlations when using four PIU subscales (preference for online relationships, use of the internet for mood regulation, deficient self-regulation, and the manifestation of negative outcomes).

Neglect, obsession and the inability to control behaviour reflect the negative impact of internet use on daily routine, which can lead to isolation from social life, loneliness and thus depression (Kaess et al., 2014; Romer, Bagdasarov and More, 2013; Yan et al., 2011). Social comparison theory (Festinger, 1954) might explain the link. Children's social comparisons (e.g., through social media) could be unrealistic, engendering feelings of failure and consequent depressive symptoms. However, the opposite direction of causation is possible: excessive internet use might be a consequence of withdrawal from social interactions. Yen et al. (2011) proposed that internet use may serve as a coping strategy for those who already suffer from depressive symptoms. This could be explained by Gámez-Guadrix who showed that 
depressive symptoms at initial assessment predicted an increased preference for online relationships, negative outcomes and mood regulation one year later.

Consistent with earlier research, poorer physical health was associated with PIU (Young \& de Abreu, 2011), and specifically for neglect and obsession, presumably reflecting the fact that daily routine activities, other than the use of internet, provide children/adolescents with the opportunity to be more physically active, maintain better dietary habits and adopt better sleeping patterns. Hyperactivity was also positively associated with PIU, in line with previous research (Gundogar et al., 2012; Kaess et al., 2014), but the present study also demonstrated that Neglect and Obsession specifically underpin the association. PIU and hyperactivity may co-occur through the mediating effect of impulsivity, a characteristic shared by both disorders (Kaess et al., 2014).Conduct problems also predicted overall PIU and higher scores for obsession and neglect in particular; like hyperactivity, conduct problems have also been linked with impulsivity (Kaess et al., 2014).

Previous research has also indicated that conduct problems, in the form of aggression, are positively associated with PIU (Li et al., 2015; Ko et al., 2009). Excessive users of the internet may develop impaired communication skills and consequent aggressive behaviour (Ghassemzadeh, et al., 2008). Although Kormas et al. (2011) argued that PIU did not affect social skills or peer relations, Lim et al., (2015) proposed that clinical factors such as depression and anxiety mediate this relationship, especially when aggressive behaviour predicts PIU. Peer problems significantly predicted lower levels of Neglect, perhaps because children who neglect social activities lack the social skills that support peer integration (Fox \& Boulton, 2011). Thus, social skills training may help strengthen peer relationships amongst these children (Bierman \& Furman, 1984). 
The more prosocial the participant the more likely they were to score high on the control disorder factor. Higher control disorder scores reflect awareness of a need to limit time online without being able to do so satisfactorily. The finding that prosocial behaviour in the normal range predicted clinical-level control disorder may relate to participants' concerns over their ability to shift from limited engagement in prosocial behaviour to greater involvement.

The total negative impact that participants' emotional and behavioural problems had on their daily activities was positively related to overall PIU and Obsession. It is understandable that those reporting higher impact of problems are also more likely to show PIU, specifically Obsession, which also reflects the impact of internet use on their psychological wellbeing (e.g., feeling depressed or stressed) when they are not using internet. Children confirm that excessive internet use and Obsession have significant impacts on activities including schoolwork and leisure. Younger participants were more likely to score high for Obsession. In contrast, previous research has indicated that older children are more vulnerable to the negative impacts of PIU (Smahel et al., 2012); the current study showed this to be the case for younger children and for Obsession only, not for neglect or total PIU, indicating that PIU is manifested differently in older versus younger children. Older children typically have a wider range of independent daily activities compared to younger children who may prefer to spend their time on the internet. Gender also showed a significant association with PIU, where male participants scored higher for total PIU and specifically for Obsession. This contradicts earlier findings that females are more prone to PIU (Durkee et al., 2012).

Finally, we categorised the factors to examine how clinical psychopathological problems predict clinical problematic internet use. It was found that anxiety 
additionally predicts clinical Obsession and Control disorder, consistent with previous research (Lee and Stapinski, 2012): anxious children may try to increase their internet use as a protective strategy to avoid anxiety. Psychosomatic problems were additional significant predictors of Neglect and Obsession in the borderline/clinical range. Internet obsession and neglect could negatively impact routine activities, e.g. eating and sleeping patterns, leading to psychosomatic problems. Those who are poorer at interacting with others in real life might use the internet to compensate, therefore being more likely to exhibit obsession.

Scores in the borderline-clinical range for substance misuse predicted total PIU, Neglect and Obsession. Substance misuse may be considered a feature of conduct problems. Children with conduct disorder have an earlier onset of substance use (Lynskey \& Fergusson, 1995), which can also lead to aggression (White, Loeber, Stouthamer-Loeber and Farrington, 1999). Internet addiction is related to social isolation and increased substance misuse (Frangos, Frangos \& Sotiropoulos, 2011; Yen, Co, Ye, Chen \& Chen, 2009). This comorbidity of addictive behaviours may indicate a cause-and-effect relationship or a shared underlying cause (Mueser, Drake \& Wallach, 1998). Here, we found that this relationship remains significant while adjusting for other psychopathologies, gender and age, suggesting that it is important. to screen for substance misuse in children/adolescents with problematic internet use as well as vice versa.

Older participants were more likely to be in the borderline-clinical range for Neglect, supporting previous research that older children are more vulnerable to the negative impacts of PIU (Smahel et al., 2012). However, this was the case for Neglect only, indicating that PIU is manifested differently in older versus younger children, 
perhaps reflecting wider range of independent daily activities, which allow more scope for PIU to disturb their routines.

These results can be explained by the self-regulation theory (Deci \& Ryan, 2000; Barnes \& Pressey, 2011; Wang, 2014). Excessive internet use provided individuals with control, autonomy, a self-presentation of themselves, and exposure and interaction with others in a controlled manner. Thus the relationship between psychological problems and PIU may be explained as arising from these basic needs of self-regulation in the context of internet use (Wong et al., 2015).

A drawback of the study is that it did not obtain data about actual time spent online or the activities conducted online. It can be assumed that those who use the internet for long hours to do their homework, for example, might have different risk factors (if any) compared to those who use it more for social networking or games (non-study related). It should be remembered that the internet is a medium, and certain online resources (e.g. social networking applications, games) might be key in predisposing problematic internet use. Such issues need further research.

To conclude, three dimensions of PIU were identified, confirmed and validated for the first time in a child and adolescent sample. These dimensions were positively associated with each other, and regression analysis demonstrated that they can predict different psychological, emotional and behavioural problems. Clinical practitioners should consider these problems when assessing children and adolescents. PIU is apparent among children as young as 10 years old; detecting the early onset of PIU may help practitioners, educators and parents tackle the problem and might prevent the development of other mental and physical health problems. 


\section{REFERENCES}

American Psychiatric Association (APA) (2013). Diagnostic and statistical manual of mental disorders (DSM-5). Retrieved from: http://www.dsm5.org

Barnes, S. J., and Pressey, A. D. (2011). Who needs cyberspace? Examining drivers of needs in Second Life. Internet Res. 21, 236-254.

Bierman, K. L. \& Furman, W. (1984). The effects of social skills training and peer involvement on the social adjustments of preadolescents. Child Development, $55,151-162$.

Chak, K., and Leung, L. (2004). Shyness and locus of control as predictors of Internet addiction and Internet use. Cyberpsychol. Behav. 7, 559-570.

Dalbudak, E., Evren, C., Aldemir, S., \& Evren, B. (2014). The severity of Internet addiction risk and its relationship with severity of borderline personality features, childhood traumas, dissociative experiences, depression and anxiety symptoms among Turkish university students. Psychiatry Research, 219, 577582.

Deci, E. L., and Ryan, R. M. (2000). The "what" and "why" of goal pursuits: human needs and the self-determination of behavior. Psychol. Inq. 11, 227-268.

Demetrovics, Z., Szeredi, B., \& Rózsa, S. (2008). The three-factor model of Internet addiction: The development of the Problematic Internet Use Questionnaire. Behavior Research Methods, 40, 563-574.

Dillman-Carpentier, F., Brown, J., Bertocci, M., Silk, J., Forbes, E., \& Dahl, R. (2008). Sad kids, sad media? Applying mood management theory to depressed adolescents' use of media. Media Psychology, 11, 143-166. 
Durkee, T., Kaess, M., Carli, V., Parzer, P., Wasserman, C., Floderus, B., et al. (2012). Prevalence of pathological Internet use among adolescents in Europe: Demographic and social factors. Addiction, 107(12), 2210-2222.

Festinger, L. (1954). A Theory of Social Comparison Processes. Human Relations, 7, 117-140.

Fox, C. L., \& Boulton, M. J. (2011). The social skills problems of victims of bullying: Self, peer and teacher perceptions. British Journal of Educational Psychology, $75,313-328$.

Frangos, C.C., Frangos, C.C., \& Sotiropoulos, I. (2011). Problematic Internet Use among Greek university students: an ordinal logistic regression with risk factors of negative psychological beliefs, pornographic sites, and online games. Cyberpsychology, Behavior, andSocial Networking, 14 (1-2) 51 - 58.

Gámez-Guadix, M. (2014). Depressive symptoms and problematic internet use among adolescents: Analysis of the longitudinal relationships from the cognitivebehavioral model. Cyberpsychology, Behavior, and Social Networking, 17 (11), 714-719.

Ghassemzadeh, L., Shahraray, M. \& Moradi A. (2008). Prevalence of internet addiction and comparison of Internet addicts and non-addicts in Iranian high schools. Cyberpsychology \& Behaviour, 11(6), 731-733.

Gini, G. (2008). Associations between bullying behaviour, psychosomatic complaints, emotional and behavioural problems. Journal of Paediatrics and Child Health, 44, 492-497.

Goodman, R,. Meltzer, H., \& Bailey, V. (1998). The strengths and difficulties questionnaire: a pilot study on the validity of the selfreport version. Eur Child Adolesc Psychiatry 7(3), 125-130. 
Griffiths, M.D. (2012). Facebook Addiction: Concerns, criticicm, and recommendations - A response to Andreassein and colleagues. Psychological Reports. 110, 518-520.

Guan, S. A., \& Subrahmanyam, K. (2009). Youth Internet use: risks and opportunities. Current Opinion in Psychiatry, 22(4), 351-356.

Gundogar, A., Bakim, B., Ozer, O.A., \& Karamustafalioglu, O. (2012). The association between internet addiction, depression and ADHD among high school students. Eur Psychiatry 27,1.

Horwitz, A. G., Hill, R. M., \& King, C. A. (2011). Specific coping behaviors in relation to adolescent depression and suicidal ideation. Journal of Adolescence, $34,1077-1085$.

$\underline{\text { Hsu, S. H., Wen, M.-H., and Wu, M.-C. (2009). Exploring user experiences as }}$ predictors of MMORPG addiction. Comput. Educ. 53, 990-999.

Iacovelli, A., \& Valenti, S. (2009). Internet addiction's effect one likeability and rapport. Computers in Human Behavior, 25(2), 439-443.

Kaess, M., Durkee, T., Brunner, R., Carli, V., Parzer, P., Wasserman, C., et al. (2014). Pathological Internet use among European adolescents: psychopathology and self-destructive behaviours. European child \& adolescent psychiatry, 23(11), $1093-1102$.

Kelley, K. J. \& Gruber, E. M. (2010). Psychometric properties of the Problematic Internet Use Questionaire. Computers in human behavior, 26, 1838-1845.

Knight, J.R., Sherritt, L., Shrier, L.A., Harris, S.K., \& Chang, G. (2002).Validity of the CRAFFT substance abuse screening test among adolescent clinic patients. Arch Pediatr Adolesc Med, 156(6), 607-14. 
Ko CH., Yen JY., Chen CS, et al. (2009).Predictive values of psychiatric symptoms for Internet addiction in adolescents: a 2-year prospective study. Archives of Pediatrics \& Adolescent Medicine 2009; 163:937-943

Ko, C.H., Yen, J.Y., Chen, C.C., Chen, S.H., Wu, K., \& Yen, C.F., (2006).

Tridimensional Personality of Adolescents With Internet Addiction and Substance Use Experience. Can J Psych, 51, 887-894

Kormas, G., Critselis, E., Janikian, M., Kafetzis, D., \& Tsitsika, A. (2011). Risk factors and psychosocial characteristics of potential problematic and problematic internet use among adolescents: A cross-sectional study. $B M C$ Public Health, 11, 595-602.

Lee, B.W., \& Stapinski, L.A. (2012). Seeking safety on the Internet: Relationship between social anxiety and problematic Internet use. Journal of Anxiety Disorders, 26(1), 197-205.

Lee, Y.S., Han, D.H., Kim, S.M., \& Renshaw, P.F., (2013). Substance abuse precedes internet addiction. Addict Behav, 38, 2022-2025.

Li, W., O'Brien, J. E., Snyder, S. M., \& Howard, M. O. (2015). Characteristics of Internet Addiction/Pathological Internet Use in U.S. University Students: A Qualitative-Method Investigation. Plos ONE, 10(2), 1-19.

Lynskey M. T.. \& Fergusson D. M. (1995). Childhood conduct problems, attention deficit behaviors, and adolescent alcohol, tobacco, and illicit drug use. Journal of Abnormal Child Psychology. 23, 281-302.

Moreno, M. A., Jelenchick, L. A. \& Breland, D. J. (2015). Exploring depression and problematic internet use among college females: a multisite study. Computers in Human Behavior, 49, 601-607. 
Mueser, K.T., Drake, R.E., \& Wallach, M.A. (1998). Dual diagnosis: A review of etiological theories. Addict. Behav. 23, 717- 734.

Nadkarni, A., and Hofmann, S. G. (2012). Why do people use Facebook? Personal. Individ. Dif. 52, 243-249.

Ofcom (2017). Children and Parents: Media Use and Attitudes Report. Retrieved from: https://www.ofcom.org.uk/_data/assets/pdf_file/0020/108182/childrenparents-media-use-attitudes-2017.pdf

Romer, D., Bagdasarov, Z., \& More, E. (2013). Older versus newer media and the well-being of United States youth: Results from a National Longitudinal Panel. Journal of Adolescent Health, 52(5), 613-619.

Rosen, L. D., Lim, A. F., Felt, J., Carrier, L. M., Cheever, N.A., Lara-Ruiz, J. M., Mendoza, J., \& Rokkum, J. (2014). Media and technology use predicts ill-being among children, preteens and teenagers independent of the negative health impacts of exercise and eating habits. Computers in Human Behavior, 35, 364375.

Smahel, D., Helsper, E., Green, L., Kalmus, V., Blinka, L. \& Ólafsson, K. (2012). Excessive internet use among European children. EU Kids Online, London School of Economics \& Political Science, London, UK.

Song, I., LaRose, R., Eastin, M. S., and Lin, C. A. (2004). Internet gratifications and internet addiction: on the uses and abuses of new media. Cyberpsychol. Behav. 7, 384-394.

Spitzer, R.L., Kroenke, K., \& Williams, J.B. (1999). Patient Health Questionnaire Primary Care Study Group. Validation and utility of a self-report version of PRIME-MD: the PHQ primary care study. JAMA. 282,1737-1744. 
Spitzer, R.L., Kroenke, K., Williams, J.B, \& Löwe, B. (2006). A brief measure for assessing generalized anxiety disorder. Arch Inern Med, 166,1092-1097.

Tonioni, F., D’Alessandris, L., Lai, C., Martinelli, D., Corvino, S., Vasale, M., et al., (2012). Internet addiction: hours spent online, behaviors and psychological symptoms. General Hospital Psychiatry, 34(1), 80-87.

Tsitsika, A., Critselis, E., Kormas, G., Filippopoulou, A., Tounissidou, D., Freskou, A., et al. (2009). Internet use and misuse: A multivariate regression analysis of the predictive factors of Internet use among Greek adolescents. European Journal of Pediatrics, 168(6), 655-665.

Weinstein, A.M., Feder, K., Rosenberg, K., Dannon, P (2014). Internet addiction criteria evidence and treatment. Chapter 5 (pp. 99-117) in Rosenberg, K.P., \& Feder, L.C. (Eds.), Behavioral Addictions: Criteria, Evidence and Treatment. Burlington Elsevier Science USA.

White H.R. Loeber R., Stouthamer-Loeber M. \& Farrington D.P. (1999).

Developmental associations between substance use and violence. Development and Psychopathology. 11, 785-803.

Wong, T. Y., Yuen, S. L., \& Li, W. O. (2015). A basic need theory approach to problematic Internet use and the mediating effect of psychological distress. Frontiers in Psychology, 5, 1562.

Yan, Fu-chun, Ya-song, Ling-di, Zhi-min, Jian-rong \& Hao Lei, (2011). Gray matter abnormalities in Internet addiction: A voxel-based morphometry study. European Journal of Radiology, 79(1),92-95.

Yen J.Y., Yen, C,F,, Wu, H.Y., Huang, C.J., Ko, C.H., (2011). Hostility in the real world and online: the effect of internet addiction, depression, and online activity. Cyberpsychol Behav Soc Netw, 14(11), 649-655 
Yen, J. Y., Yen, C. F., Chen, C. S., Tang, T. C., \& Ko, C. H. (2009). The association between adult ADHD symptoms and Internet addiction among college students: The gender difference. Cyberpsychology Behavior, 12(2), 187-191.

Young, K. S. (1998). Internet addiction: The emergence of a new clinical disorder. CyberPsychology and Behavior, 1(3), 237-244.

Young, K.S., \& de Abreu, C.N. (2011). Internet addiction: A handbook and guide to evaluation and treatment, Hoboken, NJ: John Wiley \& Sons, Inc. 


\section{Highlights:}

- Three dimensions of problematic internet use are: Neglect, Obsession and Control Disorder.

- PIU is associated with conduct problems, hyperactivity and depressive symptoms.

- Higher PIU is associated with negative impact on daily functions and physical health.

- Younger children are more likely to score higher on Obsession and lower on Neglect.

- Males show higher levels of PIU, especially Obsession. 


\title{
Problematic Internet Use and Mental Health among British Children and
}

\section{Adolescents}

\begin{abstract}
Despite concerns about the effects of internet use, little is known about how problematic internet use impacts on British children and adolescents. By adapting the Problematic Internet Use Questionnaire (PIUQ, Demetrovics et al. 2008), this study seeks its validation while studying its association with psychopathological and health problems. A sample of 1,814 children and adolescents (aged 10-16 years old) from UK schools completed questionnaires about PIU, behavioural problems, depression, anxiety and health problems. Confirmatory Factor Analysis identified three independent factors: Neglect, Obsession and Control Disorder. Using path analysis PIU was significantly predicted by conduct problems, hyperactivity, impact on daily life activities, depression and poorer physical health. Males were more likely than females to score higher on PIU. The study shows for the first time that the adapted PIU questionnaire constitutes a valid tool for the assessment of problematic internet use among children/adolescents. The results also suggest an urgent need for the development of intervention strategies.
\end{abstract}

Key words: Internet Addiction; Problematic Internet Use; Pathological Internet Use; Mental Health; Psychopathology; Children and Adolescents 


\section{INTRODUCTION}

The accessibility of online activities can lead young people to spend more time online than they originally intend (Smahel, Blinka, \& Ledabyl, 2008). In the UK, the Office of Communication (Ofcom, 2017) reported 83\% of 12-15 year olds have smart phones and 99\% go online for nearly 21 hours a week, an increase from the previous year. Increased access and persistent internet use increase the risk of developing online addictive behaviours (Tonioni et al., 2012; Tsitsika et al., 2009), which can adversely affect psychological development (Iacovelli \& Valenti, 2009; Guan, \& Subrahmanyam, 2009). Excessive internet use has attracted increasing concern, leading to the introduction of terms such as "Problematic Internet Use" (PIU) or “Internet Addiction Disorder” (IAD). Weinstein, Feder, Rosenberg and Dannon (2014) described PIU/IAD as involving controlled or excessive urges, preoccupations or behaviours regarding internet use, which results in impairment or distress to the individual. Previous studies of PIU in relation to psychopathology have adopted a wide range of research methodologies, varying in terms of design (cross-sectional vs longitudinal), sampling characteristics and measurement tools; these often constrain the kinds of conclusion that can be drawn from them.

Durkee et al. (2012) studied 11,956 adolescents from 11 European countries. Using Young's Diagnostic Questionnaire (YDQ, based on a score of 0-8) for internet addiction they classified excessive internet use into three categories; Adaptive (0-2), Maladaptive (3-4) or Pathological Internet Use ( $\geq 5$ ). In their cross-sectional survey, they found that Maladaptive Internet Use was exhibited by $13 \%$ of the sample and 4.4\% showed Pathological Internet Use. Spending more time online contributed to the pathological use. Consistently, others have also shown that long hours of internet use can negatively affect young people's schooling, family interactions, psychological 
wellbeing and physical health (Young \& de Abreu, 2011). In a longitudinal study of 14-24-year olds, $(n=719)$, excessive internet use was associated with depressive symptoms (Romer, Bagdasarov \& More, 2013). However, it has also been proposed that internet use may conversely serve as a coping mechanism for depressive feelings (Horwitz, Hill, King; 2011; Dillman-Carpentier, et al., 2008) or for a lack of physical social interaction (via social media, Griffiths, 2012). Furthermore, PIU may increase social fears and reinforce avoidance of face-to-face social interactions (Lee \& Stapinski, 2012) as well as low physical activity (Rosen et al., 2014). It is also linked with academic problems, irritability and sleep problems (Yan, et al., 2011; Young \& de Abreu, 2011).

In a large cross-sectional study of 11,356 European adolescents (approximately 15 years old on average), Kaess et al. (2014) found that pathological internet use is associated with hyperactivity/inattention, conduct problems, suicidal ideation and suicide attempts. The associations between PIU, conduct problems and hyperactivity/inattention were more robust among females than males, whereas the converse was the case for symptoms of depression, anxiety and peer relationship problems. Finally, PIU has been linked with substance abuse; indeed, it has been argued that both share similar characteristics (e.g., Ko et al. 2006; Lee et al. 2013; Dalbudak et al., 2014).

Despite extensive research highlighting the negative impacts of PIU, it is not listed in the International Classification of Diseases (ICD-10) or the Diagnostic and Statistical Manual of Mental Disorders (DSM-5), although 'Internet Gaming Disorder' has been included in DSM-5 (APA, 2013). This is a specific type of problematic internet use which aids the narrative that it is not the 'internet' itself that is addictive but what it offers (e.g. gaming, shopping etc.). The World Health Organisation (WHO) has also 
recently included the "gaming disorder" in its new draft (ICD-11). This further demonstrates the need to understand PIU as a behavioural addiction (APA, 2013). The emergence of an association between mental health and PIU can be explained by self-regulation theory (e.g., Chak \& Leung, 2004; Song et al., 2004). This theory proposes that individuals often act based on satisfying three basic needs: relatedness (desirable attachment to others) competence (sense of mastery), and autonomy (independence and satisfaction from choices made) (Deci \& Ryan, 2000). The importance of these basic needs has been studied in various settings, recently in the context of internet use (Barnes \& Pressey, 2011; Wang, 2014) and online gaming (Hsu et al., 2009). Social media use may provide a sense of relatedness and of autonomy and competence through controlled interaction online (i.e., users are in charge of what they do) (e.g., Nadkarni \& Hofmann, 2012). Wong, Yuen and Wang (2015) found that psychological distress in young adults explained the relationship between needs' satisfaction and PIU. Wong et al. (2015) recommended that psychological distress could therefore be used as an indicator of future PIU.

A number of questionnaires for problematic internet use or internet addiction have been developed, mostly based on Young's (1998) Internet Addiction Test, which was designed in accordance with DSM-IV criteria for gambling addiction. The test was further developed by Demetrovics et al. (2008) to measure the harms and problems associated with internet use (PIUQ: Problematic Internet Use Questionnaire). They evaluated their 30-item questionnaire in Hungary (1,037 respondents, 12-69 years old; $\mathrm{M}=23.3$ years), yielding 18 items (post factor analysis) across three factors, namely: Obsession (being obsessed with internet use); Neglect (neglecting non-internet activities); and Control disorder (inability to control/limit internet use). The same factors were confirmed among 280 American college students (Kelley \& Gruber, 
2010). More recently Demetrovics et al. (2016) proposed a shorter version of the PIUQ which was tested among a younger Hungarian population $(n=5,005$ aged $16-23$ years old). Using 6 items they confirmed the originally-extracted factors. The questionnaire is designed for adults and has not been tested in child samples.

Currently there is a lack of PIU research in the UK, specifically among children and adolescents; the PIUQ was chosen for investigation here due to its cultural appropriateness, and its established psychometric properties and validity. Previous research has adopted different research designs and concentrated only one or two psychological aspects; in contrast, the present study includes the analysis of different PIU subscales and how they relate to a much wider range of psychological and physical problems than has been considered previously in a UK sample.

The study has two overarching aims: first, to test the validity of the problematic internet use questionnaire (PIUQ) among British children and adolescents, something that has not been done previously; second, to examine the associations between PIU and other measures of mental and physical health, namely: depression, anxiety, emotional and behavioural problems, physical and psychosomatic health problems. To our knowledge, these factors have not previously been investigated in relation to PIU amongst children and adolescents in the UK.

\section{METHODS}

\section{Participants}

A cross-sectional research design was adopted, recruiting 1,814 participants aged 1016 years $(M=12.6$ years, $S D=1.3$ years $) ; 53 \%$ male $(M=12.5$ years, $S D=1.0$ years $)$ and $47 \%$ female $(M=12.7$ years, $S D=1.4$ years $)$. Thirty schools were contacted across the UK; however only 6 public secondary schools agreed to participate, representing only 
northern and central UK. All children/adolescents completed a hardcopy or an online version of the questionnaire; 155 questionnaires were deemed invalid or incomplete.

\section{Materials}

Demographic information included age and gender. Participants were asked to describe, on different scales, their experiences over the past 6 months. The Problematic Internet Use Questionnaire (PIUQ; 18-items), adapted from Demetrovics et al. (2008), included 15 questions categorised as: Neglect (e.g. neglecting school work), Obsession (e.g. dreaming about internet) and Control Disorder (e.g. try to limit time online). Items were answered on 5-point scales $(0=$ never; $1=$ once or twice; $2=$ once a month; $3=$ once a week and $4=$ most days $)$. Due to schools' reviews suggestions, as expert opinions, three items were removed and deemed inappropriate for young children (15-items). One item was judged as too difficult to understand (How often does it happen to you that you feel depressed, moody, or nervous when you are not on the Internet and these feelings stop once you are back online?); two others were judged inappropriate for the targeted sample (How often do you choose the Internet rather than going out with somebody to have some fun?; How often do you choose the Internet rather than being with your partner?). The Strengths and Difficulties Questionnaire (SDQ; Goodman, Meltzer, Bailey, 1998; http://www.sdqinfo.com/) is a screening tool for children aged 2-17 years old (25 items). This is a well-validated and extensively-used questionnaire; it includes 25 items measuring emotional symptoms/problems (5 items, e.g. "I am often unhappy, down-hearted or tearful") conduct problems (5 items e.g. "I fight a lot"), hyperactivity/inattention (5 items e.g. "I am restless, I cannot stay still for long”), peer problems ( 5 items, e.g. "I get on better with adults than with people my own age"), prosocial behaviour ( 5 items, e.g. "I am helpful if someone is hurt, upset or feeling 
ill"). Items were scored on a 3-points scale ("not true", "somewhat true" and "certainly true"). A further 6 items asked about whether respondents have any of the difficulties described and how these difficulties impact on their lives (e.g. "the difficulties upset or distress you"). The supplementary impact questions were scored on a 4 -point scale $(0=$ not at all; $1=$ only a little; $2=$ quite a lot and $3=$ a great deal $)$. The total for each subscale and the total difficulties (without prosocial behaviour) were calculated along with the total impact. The reliability scores for the 5 subscales ranged between $\alpha=0.81-0.92$.

The Depression questionnaire (Patient Health Questionnaire, PHQ-9, Spitzer, Kroenke, Williams, 1999) included 9 questions relating to symptoms of depression in accordance with DSM-IV (e.g. Feeling down, depressed, irritable, or hopeless?). Participants rated each item by its frequency over the past six months $(\alpha=0.90)$. The Anxiety questionnaire comprised 7 questions from GAD-7 (Spitzer, Kroenke, Williams, Löwe, 2006) measuring Generalised Anxiety Disorder using symptoms from DSM-IV (e.g. Feeling nervous, anxious or on edge.); each question reflected a particular symptom $(\alpha=0.92)$. Depression and anxiety items were scored on four-point scales $(0=$ Not at all; $1=$ Several days; $2=$ More than half of the days; $3=$ Nearly every day). A Brief Screening Test for Adolescent Substance Abuse was adapted from the CRAFFT Screening Interview (e.g. Do you ever use alcohol or drugs to relax, feel better about yourself, or fit in?). Five yes/no $(1,0)$ questions asked about substance abuse $(\alpha=0.80)$ (Knight, Sherritt, Harris, Chang, 2002) and one asked about smoking (tobacco). Finally, the Physical and Psychosomatic Health Questionnaire comprised 26 questions: 7 addressed psychosomatic problems (e.g. having nightmares) and 19 addressed physical health (e.g. having cold/cough) ( $\alpha=0.91$ and $\alpha=0.88$ respectively) (Gini, 2008). The response scale ranged from 0-4 ( $0=$ Never; $1=$ Once or twice; $2=2-3$ 
times a month; $3=$ about once a week; $4=$ several times a week $=4$ ), scores of 0 and 1 were recoded to 0 and other scores into 1 .

\section{Procedure}

Following ethical approval from Kingston University, schools sent parental consent forms and obtained agreement from the entire sample. The questionnaires were available either online (in a designated school IT room) or as hardcopy in the classroom; $70 \%$ of the children completed the online questionnaire (via Qualtrics.com) and 30\% completed the hardcopy. In both cases, the teachers gave instructions and help on how to fill in the questionnaires. Children were told that participation was voluntary and that they could withdraw at any time without explanation. Children were encouraged to provide as accurate information as possible and not to guess or "fake" their responses, and to talk to the school counselling team if they felt uncomfortable as a result of their participation.

\section{Statistical methods:}

Confirmatory Factor Analysis (CFA) via AMOS was used to validate the PIUQ. Each of the other scales described above, along with the factors extracted from the PIUQ, were individually computed and prepared for Path Analysis. All psychopathological, health variables and demographic details were included to explain variances within overall PIU and each of its dimensions. Binary Logistic Regression was used to predict participants who fall in the top $20 \%$ of the PIU scale and its dimensions (i.e. above the $80^{\text {th }}$ percentile cut-off point). Thus, PIU subscales and psychopathological problems were classified into normal $\left(<80^{\text {th }}\right.$ Percentile $)$ versus borderline-clinical $\left(>=80^{\text {th }}\right.$ percentile) categories from the overall sample (See appendix 1).

\section{Confirmatory Factor Analysis:}


Due to our different sample from Demetrovics et al. (2008) it was important to validate the adapted questionnaire. CFA was applied to confirm the 3-factor model; the model provided an adequate fit to the data while controlling for error covariance in obsession (item 5 vs. item $1 \&$ item 5 vs. item 6) and control disorder (item 1 vs. item 2) $\left(\mathrm{X}_{(83)}^{2}=439.34, \mathrm{p}<0.001, \mathrm{CFI}=0.960, \mathrm{GFI}=0.964, \mathrm{RMSEA}=0.052[0.047-\right.$ 0.057]); standardised estimates of factor loadings ranged from 0.49-0.80 (Figure 1). All three factors: neglect $(\alpha=0.81)$, obsession $(\alpha=0.83)$, control disorder $(\alpha=0.72)$ as well as the overall PIU $(\alpha=0.88)$ were reliable.

CFA was conducted across genders and age groups (children: 10-12 years; and adolescents: 13-16 years). Model fit was adequate for males $\left(\mathrm{X}_{(83)}^{2}=278.42, \mathrm{p}<0.001\right.$, $\mathrm{CFI}=0.958, \mathrm{GFI}=0.957, \mathrm{RMSEA}=0.053[0.046-0.060])$ items loaded between 0.54 to 0.80 ; and females $\left(\mathrm{X}_{(83)}^{2}=309.00, \mathrm{p}<0.001, \mathrm{CFI}=0.950, \mathrm{GFI}=0.947, \mathrm{RMSEA}=0.060\right.$ [0.053-0.067]), where loadings ranged from 0.43 to 0.80 . The model fit was adequate also for children $\left(\mathrm{X}^{2}{ }_{(83)}=296.70, \mathrm{p}<0.001, \mathrm{CFI}=0.953, \mathrm{GFI}=0.954, \mathrm{RMSEA}=0.055\right.$ [0.048-0.062]) with loadings ranging between 0.48 to 0.78 and for adolescents $\left(\mathrm{X}^{2}{ }_{(83)}=312.40, \mathrm{p}<0.001, \mathrm{CFI}=0.949, \mathrm{GFI}=0.945, \mathrm{RMSEA}=0.061[0.054-0.068]\right)$ with loadings ranging between 0.55 to 0.84 .

Insert Figure 1 Here

\section{RESULTS}

\section{Predicting Problematic Internet Use (PIU):}

Path analysis was used to examine whether or not psychological and health variables could predict PIU and its factors. Missing data and outliers were cleaned for analysis in AMOS. Table 1 shows descriptive statistics and Pearson's r correlation 
coefficients. Four separate path analysis were conducted (Table 2). The first model explained $26.2 \%$ of the variances with the overall PIU, which was significantly predicted by higher levels of conduct problems $(p<0.001)$, hyperactivity $(p<0.001)$, SDQ impact $(\mathrm{p}<0.01)$, physical health $(\mathrm{p}<0.01)$, depression $(\mathrm{p}<0.001)$ and being a male $(\mathrm{p}<0.01)$. Examining neglect, the second model explained $24.8 \%$ of the variances, where higher levels of neglect were predicted by higher levels of conduct problems $(\mathrm{p}<0.001)$, hyperactivity $(\mathrm{p}<0.001)$, physical health problems $(\mathrm{p}<0.01)$, depressive symptoms $(\mathrm{p}<0.001)$ and low levels of peer problems $(\mathrm{p}<0.001)$. For obsession, the third model explained $27.9 \%$ of the variances; higher levels for obsession were significantly predicted by higher levels of conduct problems ( $<<0.001)$, hyperactivity $(\mathrm{p}<0.01)$, SDQ impact $(\mathrm{p}<0.001)$, physical health problems $(\mathrm{p}<0.05)$ and depression $(\mathrm{p}<0.001)$. Younger participants $(\mathrm{p}<0.01)$ and males $(\mathrm{p}<0.01)$ predicted higher obsession levels. The fourth model explained $8.5 \%$ of the variance in control disorder, which was significantly predicted by higher prosocial behaviour $(\mathrm{p}<0.001)$ and depressive symptoms $(\mathrm{p}<0.001)$.

Insert Table 1 Here

Insert Table 2 Here

\section{Predicting the borderline-clinical range of PIU}

Logistic regressions (Enter method) were conducted to predict borderline-clinical PIU total and its subscales. Variables were dichotomised into the normal range (below the $80^{\text {th }}$ percentile) or the borderline/clinical range $\left(80^{\text {th }}\right.$ percentile and above).

In the first model, the likelihood of being in the borderline-clinical range of PIU was predicted by being in the borderline-clinical range for conduct problems $(\mathrm{p}<0.5)$, 
hyperactivity $(\mathrm{p}<0.001)$, SDQ impact $(\mathrm{p}<0.01)$, substance misuse $(\mathrm{p}<0.01)$, physical health $(\mathrm{p}<0.01)$ and depression $(\mathrm{p}<0.001)$.

Being in the borderline-clinical range for neglect was significantly predicted by being in the borderline-clinical range for hyperactivity $(\mathrm{p}<0.001)$, substance misuse $(\mathrm{p}<0.05)$, psychosomatic health $(\mathrm{p}<0.05)$, physical health $(\mathrm{p}<0.01)$, depression $(\mathrm{p}<0.001)$ and being in the older category $(\mathrm{p}<0.01)$.

The chances of being in the borderline-clinical range for obsession were predicted by conduct problems $(\mathrm{p}<0.001)$, hyperactivity $(\mathrm{p}<0.01)$, SDQ impact $(\mathrm{p}<0.01)$, substance misuse $(p<0.05)$, psychosomatic health $(p<0.001)$, anxiety $(p<0.05)$, depression $(\mathrm{p}<0.001)$ and being male $(\mathrm{p}<0.01)$.

Finally, being in the borderline-clinical range for control disorder was predicted by being in the clinical range of anxiety only $(\mathrm{p}<0.05)$.

Insert Table 3 Here

\section{DISCUSSION}

The adapted Problematic Internet Use questionnaire (PIUQ) yielded a factor structure that was similar to that identified in earlier studies using adult samples (Demetrovics et al., 2008; Kelley and Gruber, 2010). The factors were categorized as Neglect, Obsession and Control Disorder and were confirmed through Confirmatory Factor Analysis for different age groups (children and adolescents) and both genders. This provides a valid tool to investigate PIU among British children and adolescents. Excessive internet use is associated with neglect of daily routine (offline) activities and indicators of obsession, in which children report negative psychological impacts resulting from internet use. The control disorder factor reflects an acknowledgment of 
excessive use as a problem, and difficulties in limiting and controlling its use. All three factors were positively correlated with each other and with other psychopathologies. A strength of this study is that it looked at specific subscales in relation to previously-identified problems amongst children/adolescents. The association between PIU and "Neglect" is consistent with Young and de Abreu (2011), who reported that using the internet excessively can affect young users in terms of their social interactions with others.

In line with previous research, this study showed a significant association between overall PIU and depression (e.g. Romer, Bagdasarov \& More, 2013; Yan et al., 2011; Moreno et al., 2015). Furthermore, we found that depression is positively associated with scores on all subscales, most strongly with neglect. Gámez-Guadrix (2014) found similar positive correlations when using four PIU subscales (preference for online relationships, use of the internet for mood regulation, deficient self-regulation, and the manifestation of negative outcomes).

Neglect, obsession and the inability to control behaviour reflect the negative impact of internet use on daily routine, which can lead to isolation from social life, loneliness and thus depression (Kaess et al., 2014; Romer, Bagdasarov and More, 2013; Yan et al., 2011). Social comparison theory (Festinger, 1954) might explain the link. Children's social comparisons (e.g., through social media) could be unrealistic, engendering feelings of failure and consequent depressive symptoms. However, the opposite direction of causation is possible: excessive internet use might be a consequence of withdrawal from social interactions. Yen et al. (2011) proposed that internet use may serve as a coping strategy for those who already suffer from depressive symptoms. This could be explained by Gámez-Guadrix who showed that 
depressive symptoms at initial assessment predicted an increased preference for online relationships, negative outcomes and mood regulation one year later.

Consistent with earlier research, poorer physical health was associated with PIU (Young \& de Abreu, 2011), and specifically for neglect and obsession, presumably reflecting the fact that daily routine activities, other than the use of internet, provide children/adolescents with the opportunity to be more physically active, maintain better dietary habits and adopt better sleeping patterns. Hyperactivity was also positively associated with PIU, in line with previous research (Gundogar et al., 2012; Kaess et al., 2014), but the present study also demonstrated that Neglect and Obsession specifically underpin the association. PIU and hyperactivity may co-occur through the mediating effect of impulsivity, a characteristic shared by both disorders (Kaess et al., 2014).Conduct problems also predicted overall PIU and higher scores for obsession and neglect in particular; like hyperactivity, conduct problems have also been linked with impulsivity (Kaess et al., 2014).

Previous research has also indicated that conduct problems, in the form of aggression, are positively associated with PIU (Li et al., 2015; Ko et al., 2009). Excessive users of the internet may develop impaired communication skills and consequent aggressive behaviour (Ghassemzadeh, et al., 2008). Although Kormas et al. (2011) argued that PIU did not affect social skills or peer relations, Lim et al., (2015) proposed that clinical factors such as depression and anxiety mediate this relationship, especially when aggressive behaviour predicts PIU. Peer problems significantly predicted lower levels of Neglect, perhaps because children who neglect social activities lack the social skills that support peer integration (Fox \& Boulton, 2011). Thus, social skills training may help strengthen peer relationships amongst these children (Bierman \& Furman, 1984). 
The more prosocial the participant the more likely they were to score high on the control disorder factor. Higher control disorder scores reflect awareness of a need to limit time online without being able to do so satisfactorily. The finding that prosocial behaviour in the normal range predicted clinical-level control disorder may relate to participants' concerns over their ability to shift from limited engagement in prosocial behaviour to greater involvement.

The total negative impact that participants' emotional and behavioural problems had on their daily activities was positively related to overall PIU and Obsession. It is understandable that those reporting higher impact of problems are also more likely to show PIU, specifically Obsession, which also reflects the impact of internet use on their psychological wellbeing (e.g., feeling depressed or stressed) when they are not using internet. Children confirm that excessive internet use and Obsession have significant impacts on activities including schoolwork and leisure. Younger participants were more likely to score high for Obsession. In contrast, previous research has indicated that older children are more vulnerable to the negative impacts of PIU (Smahel et al., 2012); the current study showed this to be the case for younger children and for Obsession only, not for neglect or total PIU, indicating that PIU is manifested differently in older versus younger children. Older children typically have a wider range of independent daily activities compared to younger children who may prefer to spend their time on the internet. Gender also showed a significant association with PIU, where male participants scored higher for total PIU and specifically for Obsession. This contradicts earlier findings that females are more prone to PIU (Durkee et al., 2012).

Finally, we categorised the factors to examine how clinical psychopathological problems predict clinical problematic internet use. It was found that anxiety 
additionally predicts clinical Obsession and Control disorder, consistent with previous research (Lee and Stapinski, 2012): anxious children may try to increase their internet use as a protective strategy to avoid anxiety. Psychosomatic problems were additional significant predictors of Neglect and Obsession in the borderline/clinical range. Internet obsession and neglect could negatively impact routine activities, e.g. eating and sleeping patterns, leading to psychosomatic problems. Those who are poorer at interacting with others in real life might use the internet to compensate, therefore being more likely to exhibit obsession.

Scores in the borderline-clinical range for substance misuse predicted total PIU, Neglect and Obsession. Substance misuse may be considered a feature of conduct problems. Children with conduct disorder have an earlier onset of substance use (Lynskey \& Fergusson, 1995), which can also lead to aggression (White, Loeber, Stouthamer-Loeber and Farrington, 1999). Internet addiction is related to social isolation and increased substance misuse (Frangos, Frangos \& Sotiropoulos, 2011; Yen, Co, Ye, Chen \& Chen, 2009). This comorbidity of addictive behaviours may indicate a cause-and-effect relationship or a shared underlying cause (Mueser, Drake \& Wallach, 1998). Here, we found that this relationship remains significant while adjusting for other psychopathologies, gender and age, suggesting that it is important. to screen for substance misuse in children/adolescents with problematic internet use as well as vice versa.

Older participants were more likely to be in the borderline-clinical range for Neglect, supporting previous research that older children are more vulnerable to the negative impacts of PIU (Smahel et al., 2012). However, this was the case for Neglect only, indicating that PIU is manifested differently in older versus younger children, 
perhaps reflecting wider range of independent daily activities, which allow more scope for PIU to disturb their routines.

These results can be explained by the self-regulation theory (Deci \& Ryan, 2000; Barnes \& Pressey, 2011; Wang, 2014). Excessive internet use provided individuals with control, autonomy, a self-presentation of themselves, and exposure and interaction with others in a controlled manner. Thus the relationship between psychological problems and PIU may be explained as arising from these basic needs of self-regulation in the context of internet use (Wong et al., 2015).

A drawback of the study is that it did not obtain data about actual time spent online or the activities conducted online. It can be assumed that those who use the internet for long hours to do their homework, for example, might have different risk factors (if any) compared to those who use it more for social networking or games (non-study related). It should be remembered that the internet is a medium, and certain online resources (e.g. social networking applications, games) might be key in predisposing problematic internet use. Such issues need further research.

To conclude, three dimensions of PIU were identified, confirmed and validated for the first time in a child and adolescent sample. These dimensions were positively associated with each other, and regression analysis demonstrated that they can predict different psychological, emotional and behavioural problems. Clinical practitioners should consider these problems when assessing children and adolescents. PIU is apparent among children as young as 10 years old; detecting the early onset of PIU may help practitioners, educators and parents tackle the problem and might prevent the development of other mental and physical health problems. 


\section{REFERENCES}

American Psychiatric Association (APA) (2013). Diagnostic and statistical manual of mental disorders (DSM-5). Retrieved from: http://www.dsm5.org

Barnes, S. J., and Pressey, A. D. (2011). Who needs cyberspace? Examining drivers of needs in Second Life. Internet Res. 21, 236-254.

Bierman, K. L. \& Furman, W. (1984). The effects of social skills training and peer involvement on the social adjustments of preadolescents. Child Development, $55,151-162$.

Chak, K., and Leung, L. (2004). Shyness and locus of control as predictors of Internet addiction and Internet use. Cyberpsychol. Behav. 7, 559-570.

Dalbudak, E., Evren, C., Aldemir, S., \& Evren, B. (2014). The severity of Internet addiction risk and its relationship with severity of borderline personality features, childhood traumas, dissociative experiences, depression and anxiety symptoms among Turkish university students. Psychiatry Research, 219, 577582.

Deci, E. L., and Ryan, R. M. (2000). The "what" and "why" of goal pursuits: human needs and the self-determination of behavior. Psychol. Inq. 11, 227-268.

Demetrovics, Z., Szeredi, B., \& Rózsa, S. (2008). The three-factor model of Internet addiction: The development of the Problematic Internet Use Questionnaire. Behavior Research Methods, 40, 563-574.

Dillman-Carpentier, F., Brown, J., Bertocci, M., Silk, J., Forbes, E., \& Dahl, R. (2008). Sad kids, sad media? Applying mood management theory to depressed adolescents' use of media. Media Psychology, 11, 143-166. 
Durkee, T., Kaess, M., Carli, V., Parzer, P., Wasserman, C., Floderus, B., et al. (2012). Prevalence of pathological Internet use among adolescents in Europe: Demographic and social factors. Addiction, 107(12), 2210-2222.

Festinger, L. (1954). A Theory of Social Comparison Processes. Human Relations, 7, 117-140.

Fox, C. L., \& Boulton, M. J. (2011). The social skills problems of victims of bullying: Self, peer and teacher perceptions. British Journal of Educational Psychology, $75,313-328$.

Frangos, C.C., Frangos, C.C., \& Sotiropoulos, I. (2011). Problematic Internet Use among Greek university students: an ordinal logistic regression with risk factors of negative psychological beliefs, pornographic sites, and online games. Cyberpsychology, Behavior, andSocial Networking, 14 (1-2) 51 - 58.

Gámez-Guadix, M. (2014). Depressive symptoms and problematic internet use among adolescents: Analysis of the longitudinal relationships from the cognitivebehavioral model. Cyberpsychology, Behavior, and Social Networking, 17 (11), 714-719.

Ghassemzadeh, L., Shahraray, M. \& Moradi A. (2008). Prevalence of internet addiction and comparison of Internet addicts and non-addicts in Iranian high schools. Cyberpsychology \& Behaviour, 11(6), 731-733.

Gini, G. (2008). Associations between bullying behaviour, psychosomatic complaints, emotional and behavioural problems. Journal of Paediatrics and Child Health, 44, 492-497.

Goodman, R,. Meltzer, H., \& Bailey, V. (1998). The strengths and difficulties questionnaire: a pilot study on the validity of the selfreport version. Eur Child Adolesc Psychiatry 7(3), 125-130. 
Griffiths, M.D. (2012). Facebook Addiction: Concerns, criticicm, and recommendations - A response to Andreassein and colleagues. Psychological Reports. 110, 518-520.

Guan, S. A., \& Subrahmanyam, K. (2009). Youth Internet use: risks and opportunities. Current Opinion in Psychiatry, 22(4), 351-356.

Gundogar, A., Bakim, B., Ozer, O.A., \& Karamustafalioglu, O. (2012). The association between internet addiction, depression and ADHD among high school students. Eur Psychiatry 27,1.

Horwitz, A. G., Hill, R. M., \& King, C. A. (2011). Specific coping behaviors in relation to adolescent depression and suicidal ideation. Journal of Adolescence, $34,1077-1085$.

Hsu, S. H., Wen, M.-H., and Wu, M.-C. (2009). Exploring user experiences as predictors of MMORPG addiction. Comput. Educ. 53, 990-999.

Iacovelli, A., \& Valenti, S. (2009). Internet addiction's effect one likeability and rapport. Computers in Human Behavior, 25(2), 439-443.

Kaess, M., Durkee, T., Brunner, R., Carli, V., Parzer, P., Wasserman, C., et al. (2014). Pathological Internet use among European adolescents: psychopathology and self-destructive behaviours. European child \& adolescent psychiatry, 23(11), $1093-1102$.

Kelley, K. J. \& Gruber, E. M. (2010). Psychometric properties of the Problematic Internet Use Questionaire. Computers in human behavior, 26, 1838-1845.

Knight, J.R., Sherritt, L., Shrier, L.A., Harris, S.K., \& Chang, G. (2002).Validity of the CRAFFT substance abuse screening test among adolescent clinic patients. Arch Pediatr Adolesc Med, 156(6), 607-14. 
Ko CH., Yen JY., Chen CS, et al. (2009).Predictive values of psychiatric symptoms for Internet addiction in adolescents: a 2-year prospective study. Archives of Pediatrics \& Adolescent Medicine 2009; 163:937-943

Ko, C.H., Yen, J.Y., Chen, C.C., Chen, S.H., Wu, K., \& Yen, C.F., (2006).

Tridimensional Personality of Adolescents With Internet Addiction and Substance Use Experience. Can J Psych, 51, 887-894

Kormas, G., Critselis, E., Janikian, M., Kafetzis, D., \& Tsitsika, A. (2011). Risk factors and psychosocial characteristics of potential problematic and problematic internet use among adolescents: A cross-sectional study. $B M C$ Public Health, 11, 595-602.

Lee, B.W., \& Stapinski, L.A. (2012). Seeking safety on the Internet: Relationship between social anxiety and problematic Internet use. Journal of Anxiety Disorders, 26(1), 197-205.

Lee, Y.S., Han, D.H., Kim, S.M., \& Renshaw, P.F., (2013). Substance abuse precedes internet addiction. Addict Behav, 38, 2022-2025.

Li, W., O'Brien, J. E., Snyder, S. M., \& Howard, M. O. (2015). Characteristics of Internet Addiction/Pathological Internet Use in U.S. University Students: A Qualitative-Method Investigation. Plos ONE, 10(2), 1-19.

Lynskey M. T.. \& Fergusson D. M. (1995). Childhood conduct problems, attention deficit behaviors, and adolescent alcohol, tobacco, and illicit drug use. Journal of Abnormal Child Psychology. 23, 281-302.

Moreno, M. A., Jelenchick, L. A. \& Breland, D. J. (2015). Exploring depression and problematic internet use among college females: a multisite study. Computers in Human Behavior, 49, 601-607. 
Mueser, K.T., Drake, R.E., \& Wallach, M.A. (1998). Dual diagnosis: A review of etiological theories. Addict. Behav. 23, 717-734.

Nadkarni, A., and Hofmann, S. G. (2012). Why do people use Facebook? Personal. Individ. Dif. 52, 243-249.

Ofcom (2017). Children and Parents: Media Use and Attitudes Report. Retrieved from: https://www.ofcom.org.uk/_data/assets/pdf_file/0020/108182/childrenparents-media-use-attitudes-2017.pdf

Romer, D., Bagdasarov, Z., \& More, E. (2013). Older versus newer media and the well-being of United States youth: Results from a National Longitudinal Panel. Journal of Adolescent Health, 52(5), 613-619.

Rosen, L. D., Lim, A. F., Felt, J., Carrier, L. M., Cheever, N.A., Lara-Ruiz, J. M., Mendoza, J., \& Rokkum, J. (2014). Media and technology use predicts ill-being among children, preteens and teenagers independent of the negative health impacts of exercise and eating habits. Computers in Human Behavior, 35, 364375.

Smahel, D., Helsper, E., Green, L., Kalmus, V., Blinka, L. \& Ólafsson, K. (2012). Excessive internet use among European children. EU Kids Online, London School of Economics \& Political Science, London, UK.

Song, I., LaRose, R., Eastin, M. S., and Lin, C. A. (2004). Internet gratifications and internet addiction: on the uses and abuses of new media. Cyberpsychol. Behav. 7, 384-394.

Spitzer, R.L., Kroenke, K., \& Williams, J.B. (1999). Patient Health Questionnaire Primary Care Study Group. Validation and utility of a self-report version of PRIME-MD: the PHQ primary care study. JAMA. 282,1737-1744. 
Spitzer, R.L., Kroenke, K., Williams, J.B, \& Löwe, B. (2006). A brief measure for assessing generalized anxiety disorder. Arch Inern Med, 166,1092-1097.

Tonioni, F., D’Alessandris, L., Lai, C., Martinelli, D., Corvino, S., Vasale, M., et al., (2012). Internet addiction: hours spent online, behaviors and psychological symptoms. General Hospital Psychiatry, 34(1), 80-87.

Tsitsika, A., Critselis, E., Kormas, G., Filippopoulou, A., Tounissidou, D., Freskou, A., et al. (2009). Internet use and misuse: A multivariate regression analysis of the predictive factors of Internet use among Greek adolescents. European Journal of Pediatrics, 168(6), 655-665.

Weinstein, A.M., Feder, K., Rosenberg, K., Dannon, P (2014). Internet addiction criteria evidence and treatment. Chapter 5 (pp. 99-117) in Rosenberg, K.P., \& Feder, L.C. (Eds.), Behavioral Addictions: Criteria, Evidence and Treatment. Burlington Elsevier Science USA.

White H.R. Loeber R., Stouthamer-Loeber M. \& Farrington D.P. (1999). Developmental associations between substance use and violence. Development and Psychopathology. 11, 785-803.

Wong, T. Y., Yuen, S. L., \& Li, W. O. (2015). A basic need theory approach to problematic Internet use and the mediating effect of psychological distress. Frontiers in Psychology, 5, 1562.

Yan, Fu-chun, Ya-song, Ling-di, Zhi-min, Jian-rong \& Hao Lei, (2011). Gray matter abnormalities in Internet addiction: A voxel-based morphometry study. European Journal of Radiology,79(1),92-95.

Yen J.Y., Yen, C,F,, Wu, H.Y., Huang, C.J., Ko, C.H., (2011). Hostility in the real world and online: the effect of internet addiction, depression, and online activity. Cyberpsychol Behav Soc Netw, 14(11), 649-655 
Yen, J. Y., Yen, C. F., Chen, C. S., Tang, T. C., \& Ko, C. H. (2009). The association between adult ADHD symptoms and Internet addiction among college students: The gender difference. Cyberpsychology Behavior, 12(2), 187-191.

Young, K. S. (1998). Internet addiction: The emergence of a new clinical disorder. CyberPsychology and Behavior, 1(3), 237-244.

Young, K.S., \& de Abreu, C.N. (2011). Internet addiction: A handbook and guide to evaluation and treatment, Hoboken, NJ: John Wiley \& Sons, Inc. 


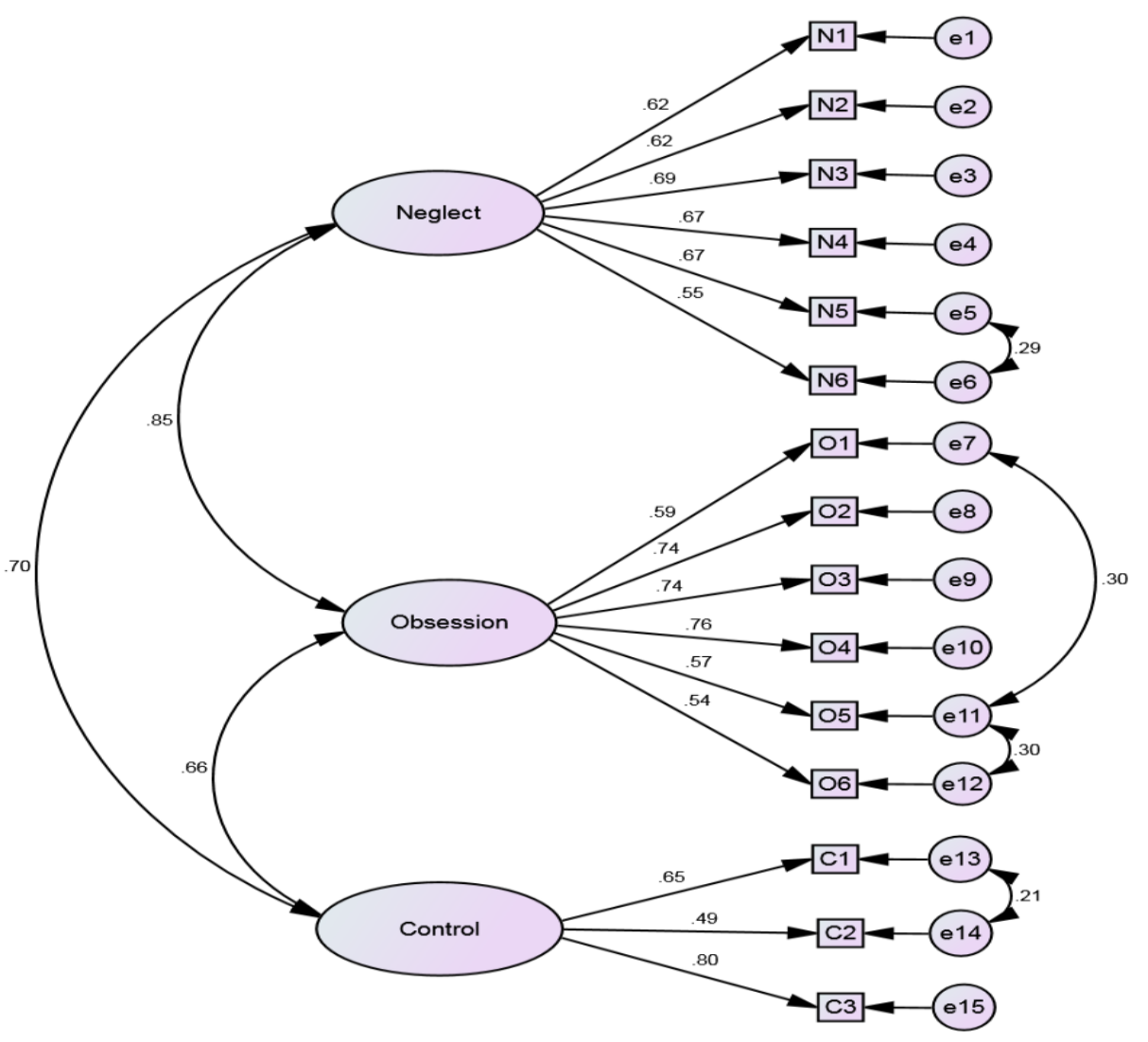

Figure 1: CFA for the 3-factors of the current sample 

Table 1: Descriptive for total scores and correlations between predictors

\begin{tabular}{|c|c|c|c|c|c|c|c|c|c|c|c|c|c|c|c|c|}
\hline & Mean & SD & 1 & 2 & 3 & 4 & 5 & 6 & 7 & 8 & 9 & 10 & 11 & 12 & 13 & 14 \\
\hline 1-PIU & 10.88 & 10.61 & & & & & & & & & & & & & & \\
\hline 2-Neglect & 5.67 & 5.48 & $.916^{* *}$ & & & & & & & & & & & & & \\
\hline 3-Obsession & 2.18 & 3.94 & $.853 * *$ & $.683^{* *}$ & & & & & & & & & & & & \\
\hline 4-Control & 3.04 & 3.12 & $.713 * *$ & $.495^{* *}$ & $.439^{* *}$ & & & & & & & & & & & \\
\hline 5-Emotional Symptoms & 2.51 & 2.34 & $.292 * *$ & $.250^{* *}$ & $.316^{* *}$ & $.154^{* *}$ & & & & & & & & & & \\
\hline 6-Conduct Problems & 2.00 & 1.77 & $.296 * *$ & $.289^{* *}$ & $.353^{* *}$ & $.052^{*}$ & $.345^{* *}$ & & & & & & & & & \\
\hline 7-Hyperactivity & 3.69 & 2.21 & $.296 * *$ & $.315^{* *}$ & $.302^{* *}$ & $.071^{* *}$ & $.303^{* *}$ & $.536^{* *}$ & & & & & & & & \\
\hline 8-Peer Problems & 1.90 & 1.60 & $.150 * *$ & $.106^{* *}$ & $.231^{* *}$ & .030 & $.377^{* *}$ & $.359^{* *}$ & $.206^{* *}$ & & & & & & & \\
\hline 9-Prosocial behaviour & 6.90 & 2.21 & -.030 & $-.075^{* *}$ & $-.069^{* *}$ & $.117^{* *}$ & $.126^{* *}$ & $-.243^{* *}$ & $-.220^{* *}$ & $-.204^{* *}$ & & & & & & \\
\hline 10-SDQ Impact & .60 & 1.14 & $.299 * *$ & $.242^{* *}$ & $.343^{* *}$ & $.156^{* *}$ & $.320^{* *}$ & $.232^{* *}$ & $.191^{* *}$ & $.200^{* *}$ & -.036 & & & & & \\
\hline 11-Substance use & .29 & .96 & $.189 * *$ & $.179^{* *}$ & $.202^{* *}$ & $.076^{* *}$ & $.141^{* *}$ & $.274^{* *}$ & $.229^{* *}$ & $.136^{* *}$ & $-.189^{* *}$ & $.297^{* *}$ & & & & \\
\hline 12-Psychosomatic Health & .66 & 1.23 & $.317^{* *}$ & $.295^{* *}$ & $.329^{* *}$ & $.144^{* *}$ & $.482^{* *}$ & $.277^{* *}$ & $.260^{* *}$ & $.271^{* *}$ & -.016 & $.377^{* *}$ & $.246^{* *}$ & & & \\
\hline 13-Physical Health & 2.56 & 3.28 & $.335^{* *}$ & $.324^{* *}$ & $.330^{* *}$ & $.153^{* *}$ & $.453^{* *}$ & $.307^{* *}$ & $.305^{* *}$ & $.194^{* *}$ & -.014 & $.332^{* *}$ & $.225^{* *}$ & $.493^{* *}$ & & \\
\hline 14-Anxiety & 2.30 & 3.74 & $.365^{* *}$ & $.334^{* *}$ & $.352^{* *}$ & $.211^{* *}$ & $.603^{* *}$ & $.256^{* *}$ & $.233^{* *}$ & $.304^{* *}$ & .028 & $.514^{* *}$ & $.242^{* *}$ & $.525^{* *}$ & $.457^{* *}$ & \\
\hline 15-Depression & 3.27 & 4.78 & $.456^{* *}$ & $.432^{* *}$ & $.427^{* *}$ & $.252^{* *}$ & $.555^{* *}$ & $.287^{* *}$ & $.299^{* *}$ & $.295^{* *}$ & -.027 & $.489^{* *}$ & $.267^{* *}$ & $.561^{* *}$ & $.514^{* *}$ & $.783^{* *}$ \\
\hline
\end{tabular}

15-Depression

$3.27 \quad 4.78 \quad .456$ 
Table 2: Predicting PIU and its dimensions through Path Analysis

\begin{tabular}{|c|c|c|c|c|c|c|c|c|}
\hline & \multicolumn{2}{|c|}{ Overall PIU } & \multicolumn{2}{|c|}{ Neglect } & \multicolumn{2}{|c|}{ Obsession } & \multicolumn{2}{|c|}{ Control DisordeI } \\
\hline & Estimate & S.E & Estimate & S.E & Estimate & S.E & Estimate & S.E \\
\hline Emotional Symptoms & -.022 & .139 & -.081 & .073 & .062 & .051 & -.003 & .046 \\
\hline Conduct Problems & $.667 * * *$ & .168 & $.351 * * *$ & .088 & $333 * * *$ & .062 & -.017 & .055 \\
\hline Hyperactivity & $.523 * * *$ & .127 & $.347 * * *$ & .066 & $.146 * *$ & .047 & .030 & .042 \\
\hline Peer Problems & -.239 & .165 & $-.266 * *$ & .086 & .079 & .061 & -.052 & .054 \\
\hline Prosocial behaviour & .212 & .116 & -.002 & .061 & .021 & .043 & $.194 * * *$ & .038 \\
\hline SDQ Impact & $.672 * *$ & .243 & .074 & .126 & $.483 * * *$ & .089 & .115 & .080 \\
\hline Substance Misuse & .198 & .267 & .018 & .139 & .117 & .098 & .064 & .088 \\
\hline Psychosomatic Health & -.007 & .279 & -.009 & .146 & .070 & .103 & -.069 & .092 \\
\hline Physical Health & $.289 * *$ & .101 & $.162 * *$ & .053 & $.089 *$ & .037 & .038 & .033 \\
\hline Anxiety & -.032 & .108 & -.004 & .056 & -.042 & .040 & .014 & .035 \\
\hline Depression & $.754 * * *$ & .083 & $.396 * * *$ & .043 & $.214 * * *$ & .030 & $.144 * * *$ & .027 \\
\hline Age (10-16) & -.041 & .186 & .134 & .097 & $-.220 * *$ & .068 & .044 & .061 \\
\hline Gender (Boys/Girls) & $-1.284 * *$ & .492 & -.439 & .256 & $-.588 * *$ & .181 & -.257 & .161 \\
\hline Sqrd. Multiple Correlations & .262 & & .248 & & .279 & & .085 & \\
\hline
\end{tabular}

$* P<0.05, * * P<0.01 * * * P<0.001$ 
Table 3: Summary of Logistic Regression predicting neglect, obsession, control disorder and total PIU

\begin{tabular}{|c|c|c|c|c|c|c|c|c|c|c|c|c|}
\hline & \multicolumn{3}{|c|}{ Overall PIU } & \multicolumn{3}{|c|}{ Neglect } & \multicolumn{3}{|c|}{ Obsession } & \multicolumn{3}{|c|}{ Control Disorder } \\
\hline & $\mathrm{B}$ & S.E. & $\operatorname{Exp}(B)$ & $\mathrm{B}$ & S.E. & $\operatorname{Exp}(\mathrm{B})$ & $\mathrm{B}$ & S.E. & $\operatorname{Exp}(\mathrm{B})$ & $\mathrm{B}$ & S.E. & $\operatorname{Exp}(B)$ \\
\hline Emotional Symptoms & .077 & .176 & 1.080 & -.012 & .173 & .989 & .156 & .174 & 1.169 & -.081 & .167 & .923 \\
\hline Conduct Problems & $.362 *$ & .161 & 1.437 & .275 & .156 & 1.316 & $.553 * * *$ & .157 & 1.738 & .105 & .152 & 1.111 \\
\hline Hyperactivity & $.676^{* * *}$ & .153 & 1.966 & $.773 * * *$ & .146 & 2.166 & $.422 * *$ & .152 & 1.524 & .074 & .144 & 1.077 \\
\hline Peer Problems & .025 & .159 & 1.026 & -.166 & .156 & .847 & .137 & .154 & 1.147 & -.026 & .146 & .974 \\
\hline Prosocial Problems & -.171 & .174 & .843 & .043 & .163 & 1.044 & .055 & .167 & 1.056 & -.268 & .160 & .765 \\
\hline SDQ Impact & $.577^{* *}$ & .190 & 1.780 & .344 & .191 & 1.411 & $.568^{* *}$ & .190 & 1.765 & .306 & .191 & 1.358 \\
\hline Substance Misuse & $.567^{* *}$ & .192 & 1.762 & $.416^{*}$ & .187 & 1.516 & $.481 *$ & .193 & 1.617 & .005 & .193 & 1.005 \\
\hline Psychosomatic Health & .219 & .167 & 1.245 & $.341 *$ & .160 & 1.406 & $.568 * * *$ & .161 & 1.764 & .191 & .153 & 1.211 \\
\hline Physical Health & $.454 * *$ & .165 & 1.574 & $.428^{* *}$ & .160 & 1.534 & .299 & .164 & 1.349 & .095 & .157 & 1.100 \\
\hline Anxiety & .350 & .199 & 1.419 & .183 & .197 & 1.200 & $.388^{*}$ & .197 & 1.474 & $.401 *$ & .191 & 1.494 \\
\hline Depression & $.753 * * *$ & .188 & 2.123 & $.770 * * *$ & .183 & 2.160 & $.684 * * *$ & .187 & 1.981 & .304 & .184 & 1.355 \\
\hline Age (10-12/13-16) & .179 & .144 & 1.196 & $.443 * *$ & .138 & 1.558 & -.221 & .144 & .802 & .079 & .128 & 1.082 \\
\hline Gender(Boys/Girls) & -.158 & .149 & .853 & -.147 & .143 & .863 & $-.453 * *$ & .149 & .636 & -.088 & .131 & .916 \\
\hline Cox \& Snell $R^{2}$ & .165 & & & .148 & & & .174 & & & .033 & & \\
\hline Nagelkerke $R^{2}$ & .260 & & & .229 & & & .270 & & & .051 & & \\
\hline
\end{tabular}

$* P<0.05, * * P<0.01 * * * P<0.001$ 
Running Title: Problematic Internet Use and Mental Health in Children

Title: Problematic Internet Use and Mental Health among British Children and Adolescents

Aiman El Asam, Muthanna Samara* \& Philip Terry

Dr. Aiman EL Asam

Email: A.Elasam@,kingston.ac.uk

*Professor Muthanna Samara (correspondence author)

Email: M.Samara@Kingston.ac.uk.

Tel: +44 (0) 2084172533

Professor Philip Terry

Email: $\underline{\text { P.Terry@kingston.ac.uk }}$

Address for all authors:

Department of Psychology, Kingston University London, Penrhyn Road, Kingston upon Thames KT1 2EE, United Kingdom

\section{Declarations}

\section{Role of Funding Source:}

Funding for this study was provided by the Qatar National Research Fund (QNRF) a member of Qatar Foundation Doha, Qatar, National Priority Research Programs (NPRP) under Grant (NPRP 5-1134-3-240). QNRF had no role in the study design, collection, analysis or interpretation of the data, writing the manuscript, or the decision to submit the paper for publication.

\section{Contributors:}

Dr. Aiman El Asam: Conception and design; acquisition of data; analysis and interpretation; drafting of manuscript.

Professor Muthanna Samara: Conception and design; funding acquisition; acquisition of data; analysis and interpretation; drafting of manuscript; revising critically for important intellectual content.

Professor Philip Terry: Conception and design; revising critically for important 
intellectual content.

\section{Conflict of Interest:}

All authors confirm that there is no actual or potential conflict of interest. Personal relationships with individuals or organisations did not have any influence on the submitted research manuscript.

\section{Acknowledgements:}

The authors would like to thank Qatar National Research Fund (QNRF) a member of Qatar Foundation Doha, Qatar, National Priority Research Programs (NPRP) under Grant (NPRP 5-1134-3-240) for their support in this project. We would like also to thank all the schools, teachers and children for their time and willingness to participate in this research study. 
Appendix 1:

\begin{tabular}{cccc}
\hline & $\begin{array}{c}\text { Normal Range }\left(<\mathbf{8 0}^{\text {th }}\right. \\
\text { Percentile) }\end{array}$ & $\begin{array}{c}\text { Borderline Range }^{\mathbf{8 9}^{\text {th }} \text { Percentile) }} \\
\text { th }\end{array}$ & $\begin{array}{c}\text { Clinical Range }\left(\mathbf{Q 9 0} \mathbf{t}^{\text {th }}\right. \\
\text { Percentile })\end{array}$ \\
\hline PIU & $0-17$ & $18-24$ & $25-60$ \\
Neglect & $0-9$ & $10-13$ & $14-24$ \\
Obsession & $0-3$ & $4-6$ & $7-24$ \\
Control & $0-5$ & $6-7$ & $8-12$ \\
Emotional Symptoms & $0-3$ & $4-5$ & $6-10$ \\
Conduct Problems & $0-2$ & $3-4$ & $5-10$ \\
Hyperactivity & $0-4$ & $5-6$ & $7-10$ \\
Peer Problems & $0-2$ & $3-4$ & $4-9$ \\
Prosocial Behaviour (-) & $6-10$ & $4-5$ & $0-3$ \\
SDQ Impact & 0 & 1 & $2-10$ \\
Psychosomatic Health & 0 & 1 & $2-7$ \\
Physical Health & $0-3$ & $4-6$ & $7-19$ \\
Anxiety & $0-3$ & $4-6$ & $7-18$ \\
Depression & $0-4$ & $5-8$ & $9-27$ \\
\hline
\end{tabular}

